\title{
A (RE)CONSTRUÇÃo da AUTOIMAGEM KaLANKó
}

José MOISÉS DE OLIVEIRA SILVA ${ }^{1}$

No imaginário popular, o índio é representado por extremos, em alguns momentos como ser "irracional" e "selvagem" (LAPLANTINE, 2007), em outros como na literatura de José de Alencar, em 0 Guarani

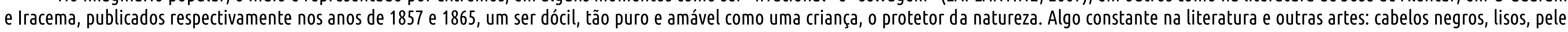

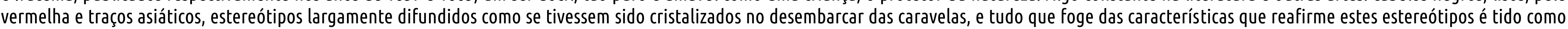
não "autêntico". Por isso, a necessidade de abordar a (re)construção da autoimagem Kalankó, tanto pelo processo histórico nacional quanto sua ressurgência.

0 que por muito se pensou é que estes grupos estariam completamente "extintos", como observa Arruti (1995, p. 57). Quanto a esse equívoco, "seus grupos teriam sido exterminados ou assimilados

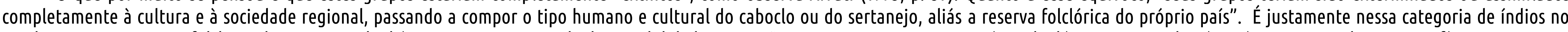

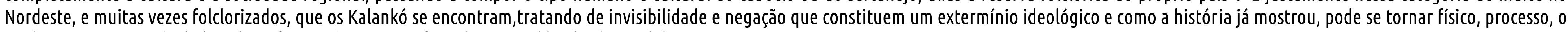
qual, grupos no Semiárido brasileiro foram vítimas, significando o etnocídio de alguns deles.

Em alguns momentos temos a figura do índio partilhando elementos com personagens do "folclore", como o Saci-pererê, Curupira, larae a Vitória-Régia, grande parte mitos de alguns grupos que são

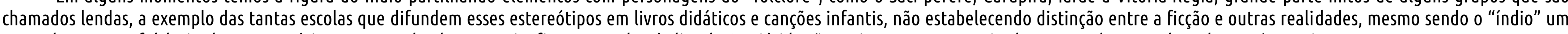

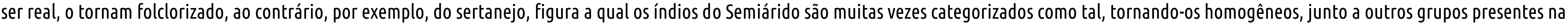

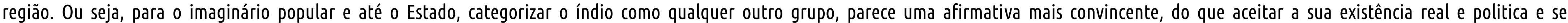

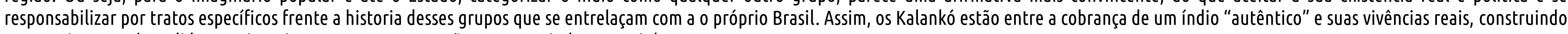
sua autoimagem, à medida que vivenciam seus processos, e vão se construindo no caminhar. 
As coisas vividas pelos Kalankó são partilhadas entre os grupos e com aqueles que residem nas mesmas comunidades. Parte destes não índios partilha elementos característicos à região, sejam referentes a

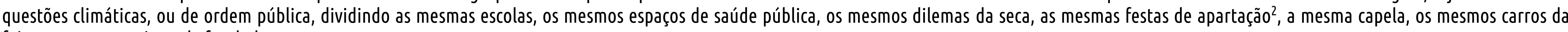
feira e os mesmos times de futebol.

Os Kalankó foram vistos de forma indistinta até 0 ano de 1998, data de sua ressurgência pública enquanto grupo indígenaKalankó. 0s chamados não índiosque com eles dividem o mesmo

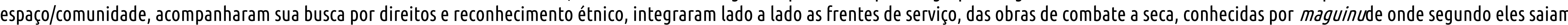

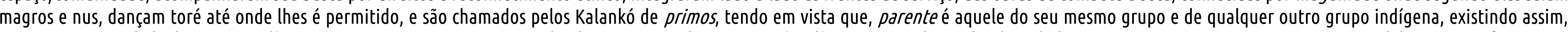

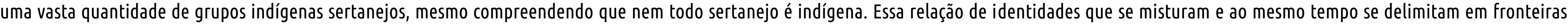

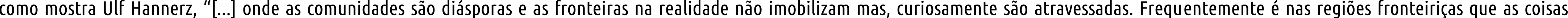
acontecem" (HANNERZ, 1997, p.08)

0 toré, enquanto elemento de afirmação étnica é um dos fatores que marcam as fronteiras, sendo a característica diacrítica, como afirma Fredrik Barth (1998),que serve tanto como elemento de distinção

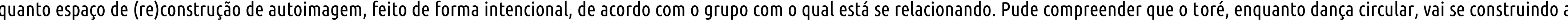
partir do seu nível de "importância", com teor político, religioso, cultural ou recreativo, onde nenhuma dessas categorias exclui a outra.

A ressurgência Kalankó é um ponto crucial para sua distinção, enquanto grupo étnico, e sua reorganização política, interna e externa, a partir da (re)construção da autoimagem, para a reinvindicação de

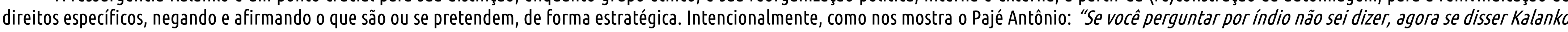

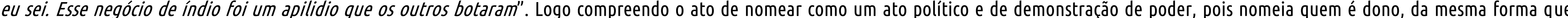

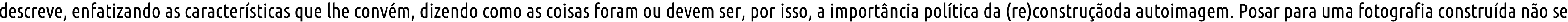
trata de ser ingenuamente manipulado, e sim, compor a categoria índios, mesmo que com sua distinção Kalankó. 
REFERÊNCIAS

ARRUTI, José Maurício Andion. Morte e vida do Nordeste indígena: a emergência étnica como fenômeno histórico regional. Estudos Históricos, Rio de Janeiro, v. 8, n. 15, 1995, p. 57.94 .

LAPLATINE, Francois. Aprender Antropologia. São Paulo: Brasiliense, 2007.

HANNERZ, Ulf. Fluxos,fronteiras e híbridos: palavras-chave da Antropologia Transnacional. Mana, v. 3, n. 1, 1997, p. 7-39. 


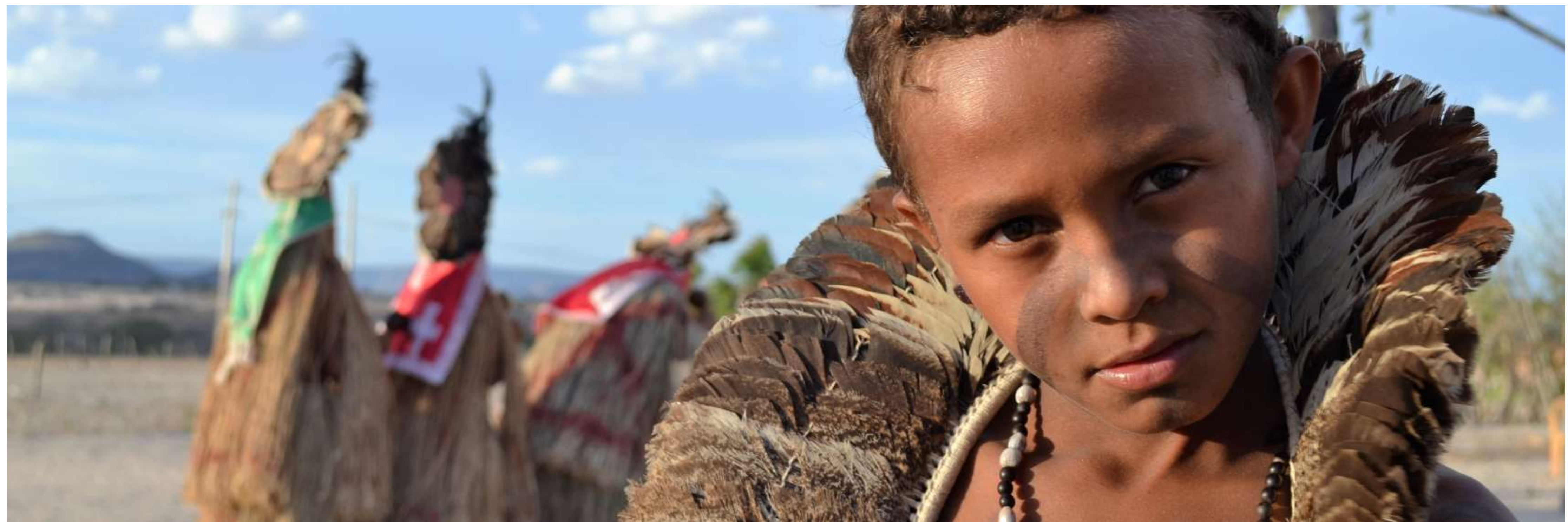

Criança Kalankó assistindo ritual de Praiá 


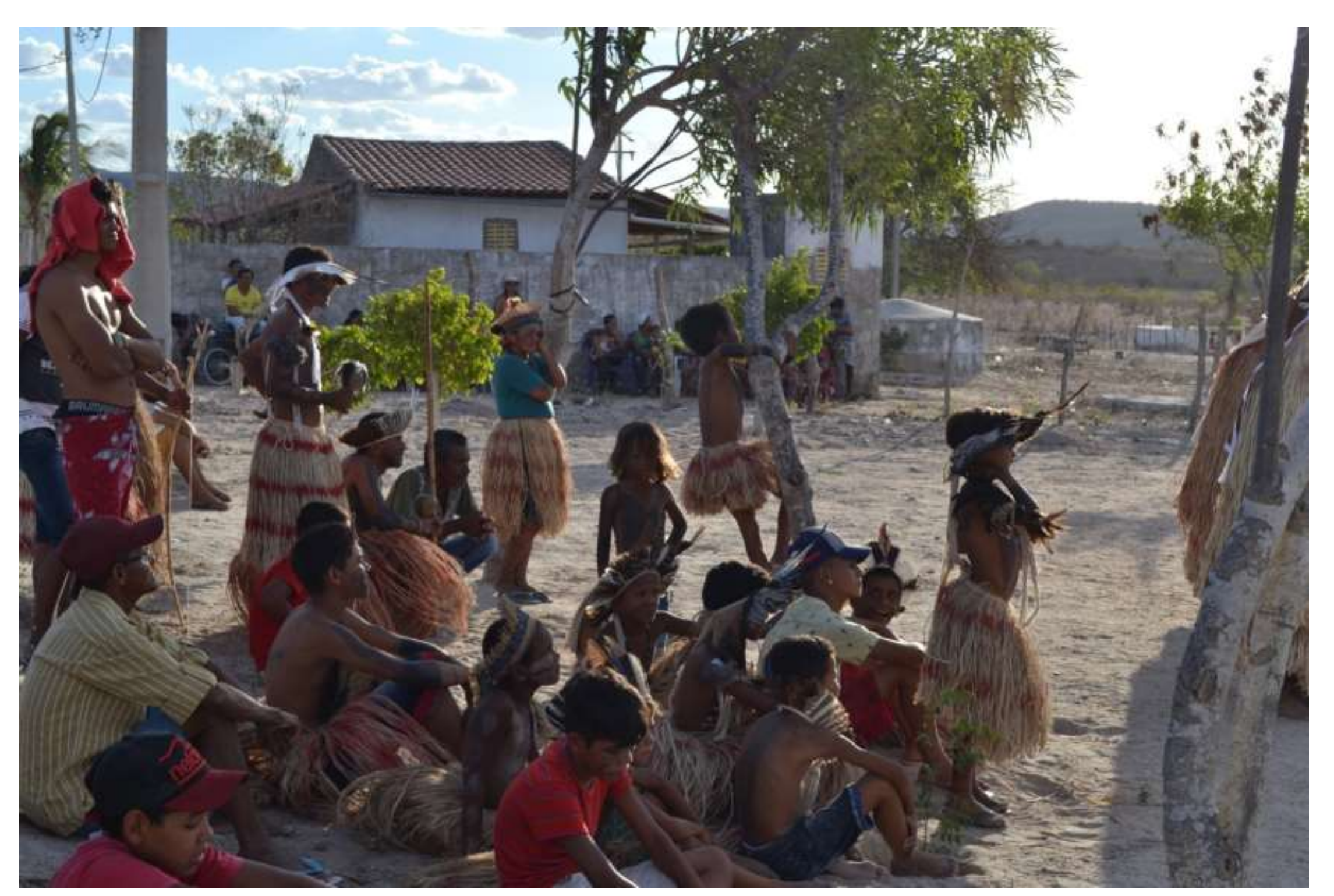

W

(4)

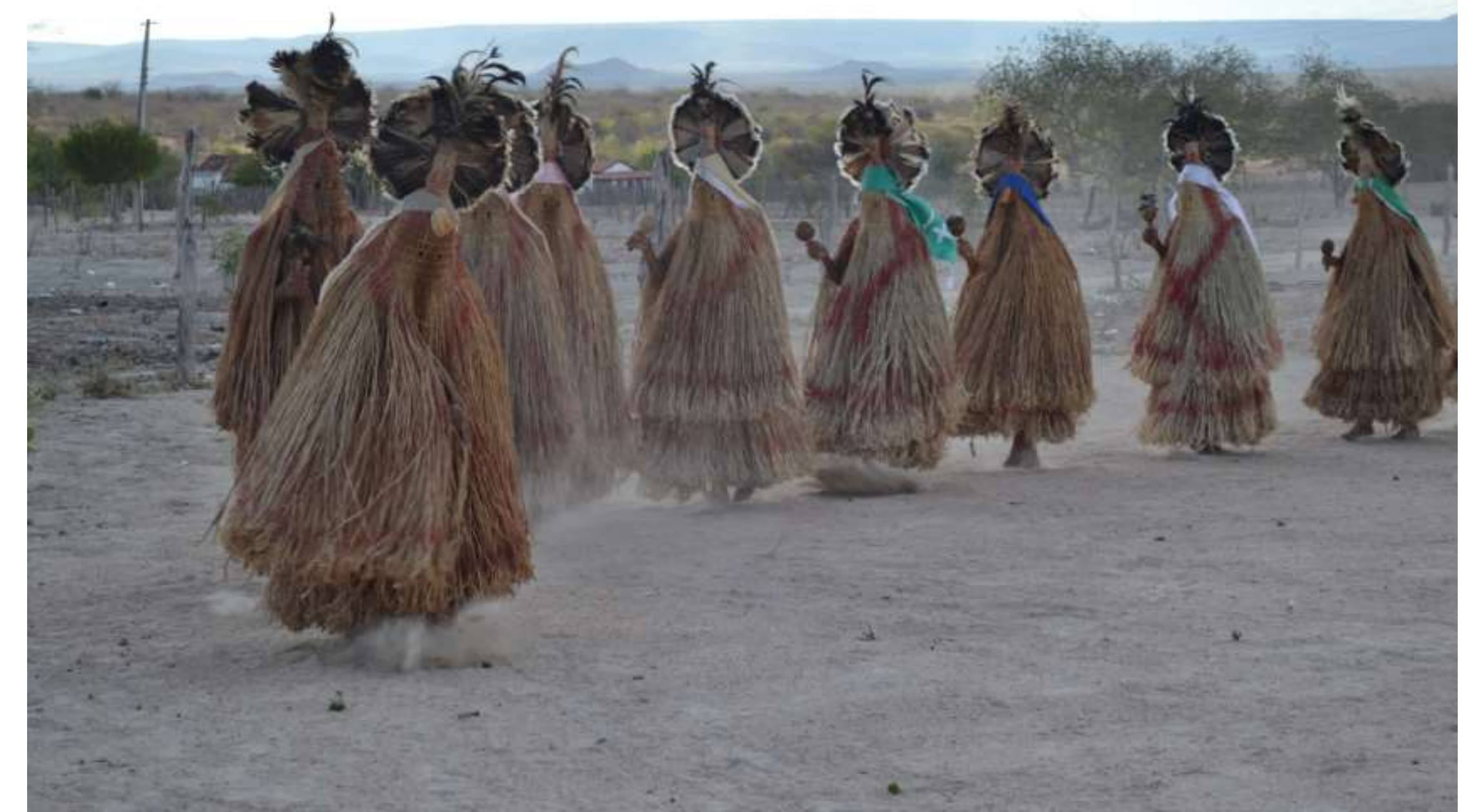




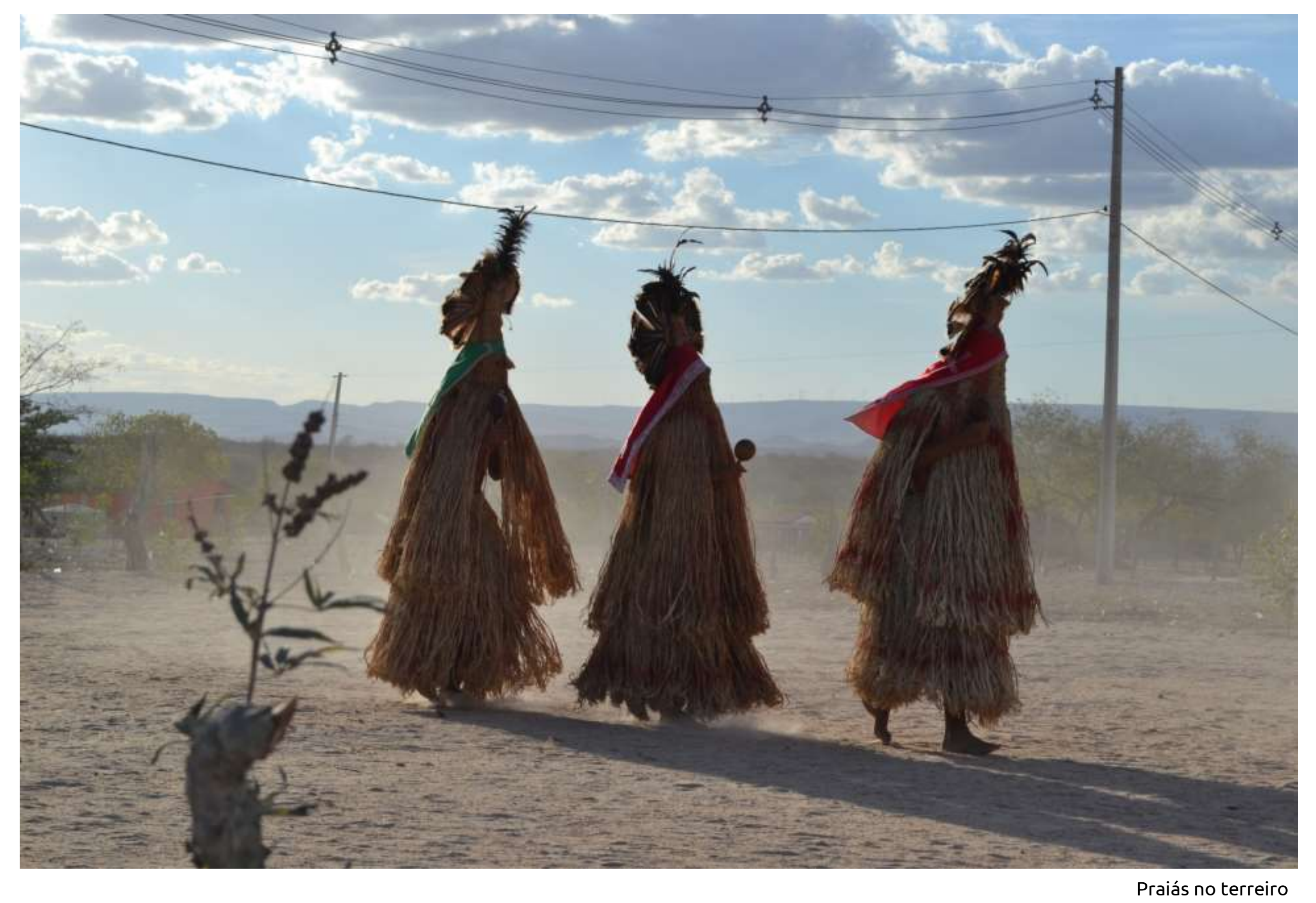




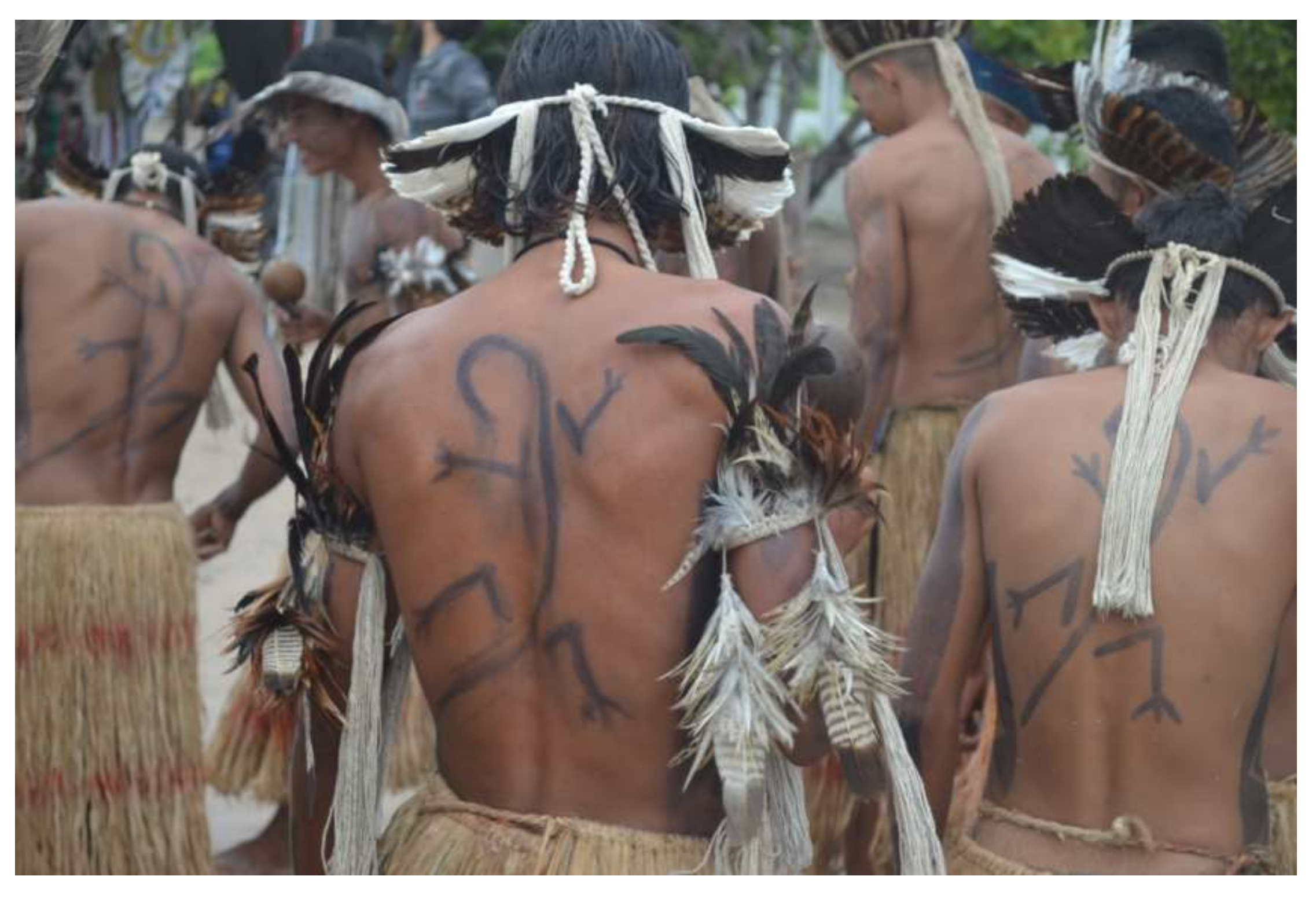

Jovem kalankó com pintura corporal de um calango, imagem adotada

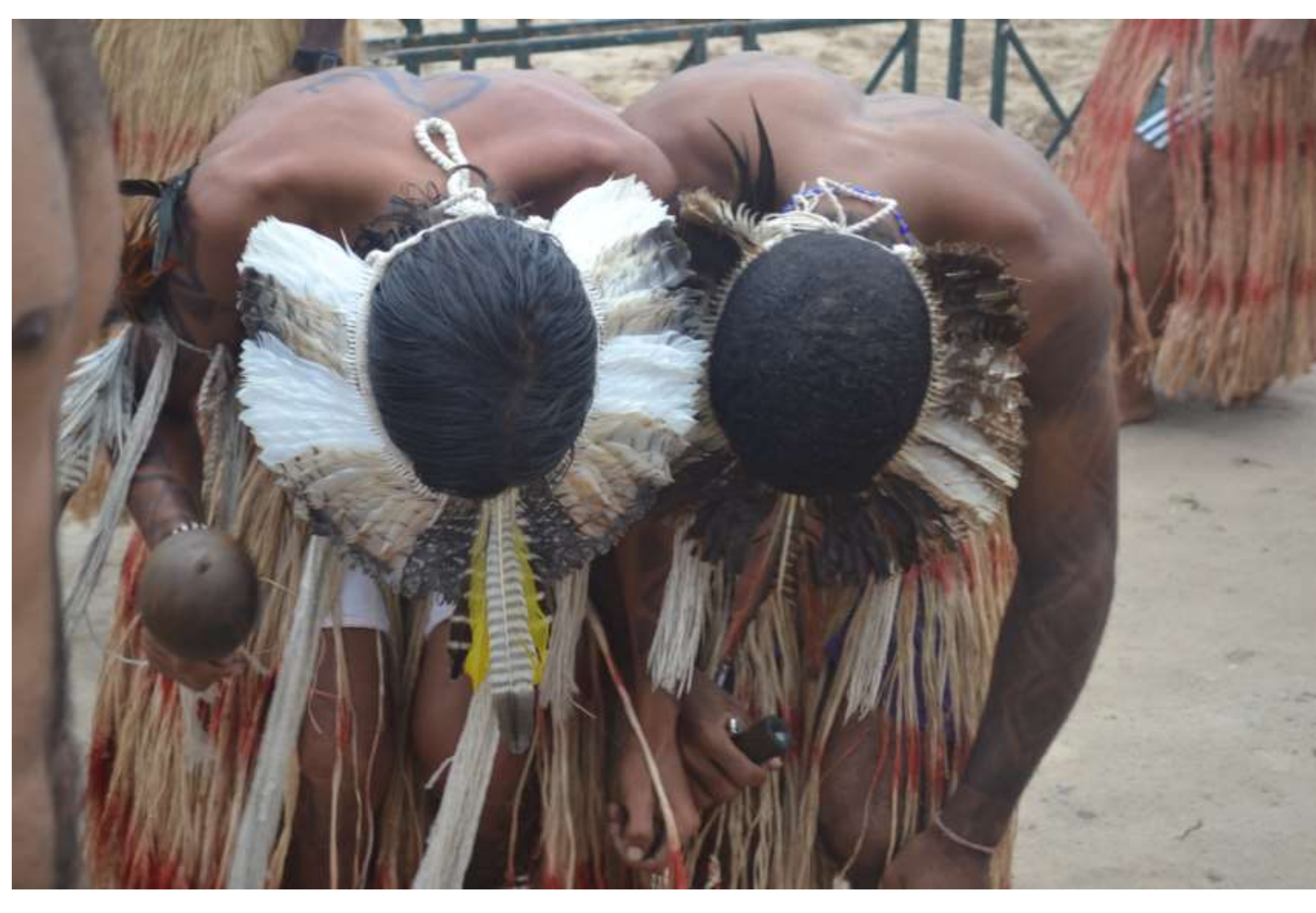

Jovens dançando toré durante comemoração dos 19 anos de resistência(2017) ano da ressurgência e reafirmação étnica do grupo 


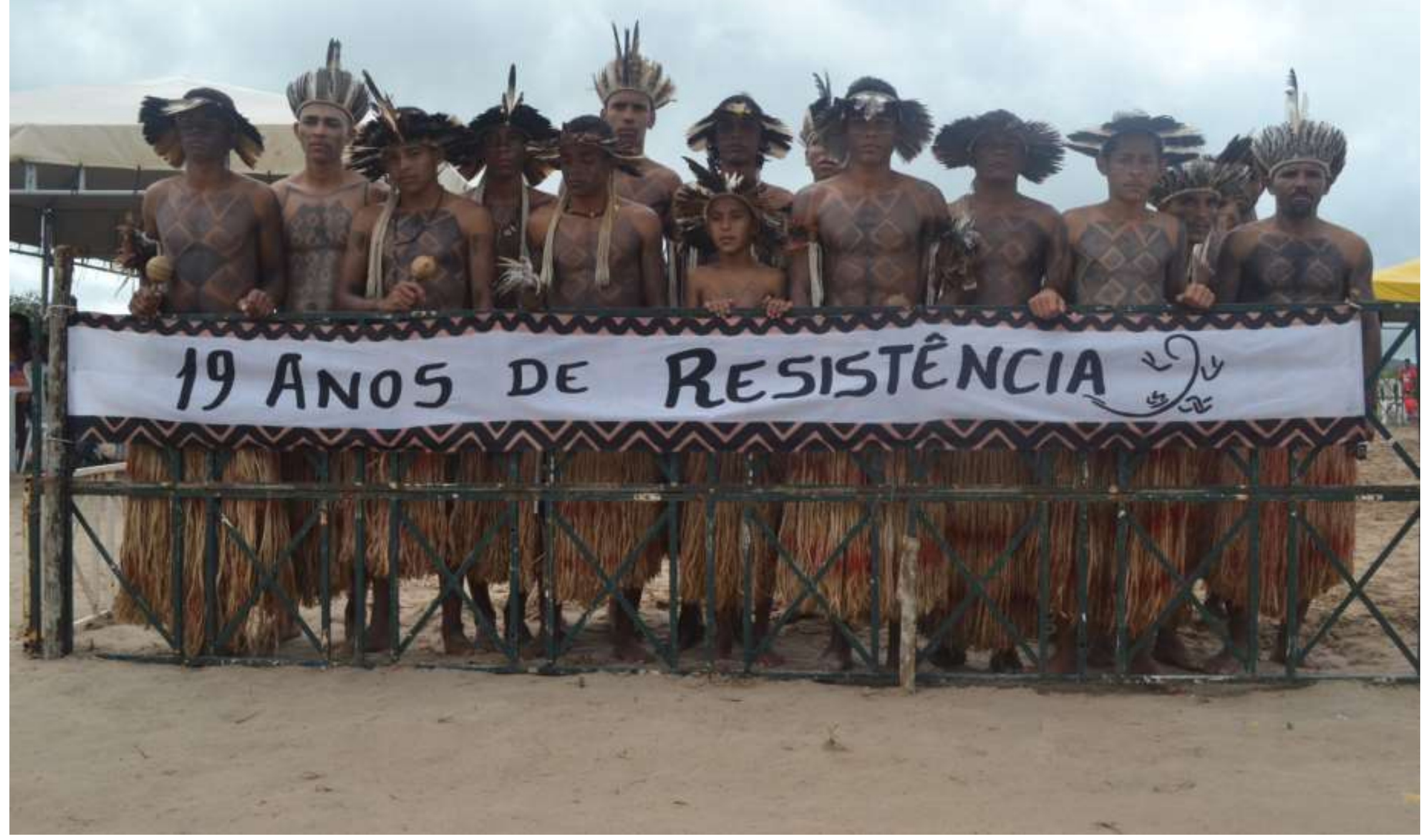

Jovens dançando toré durante comemoração dos 19 anos de resistência(2017) ano da ressurgência e reafirmação étnica do grupo 


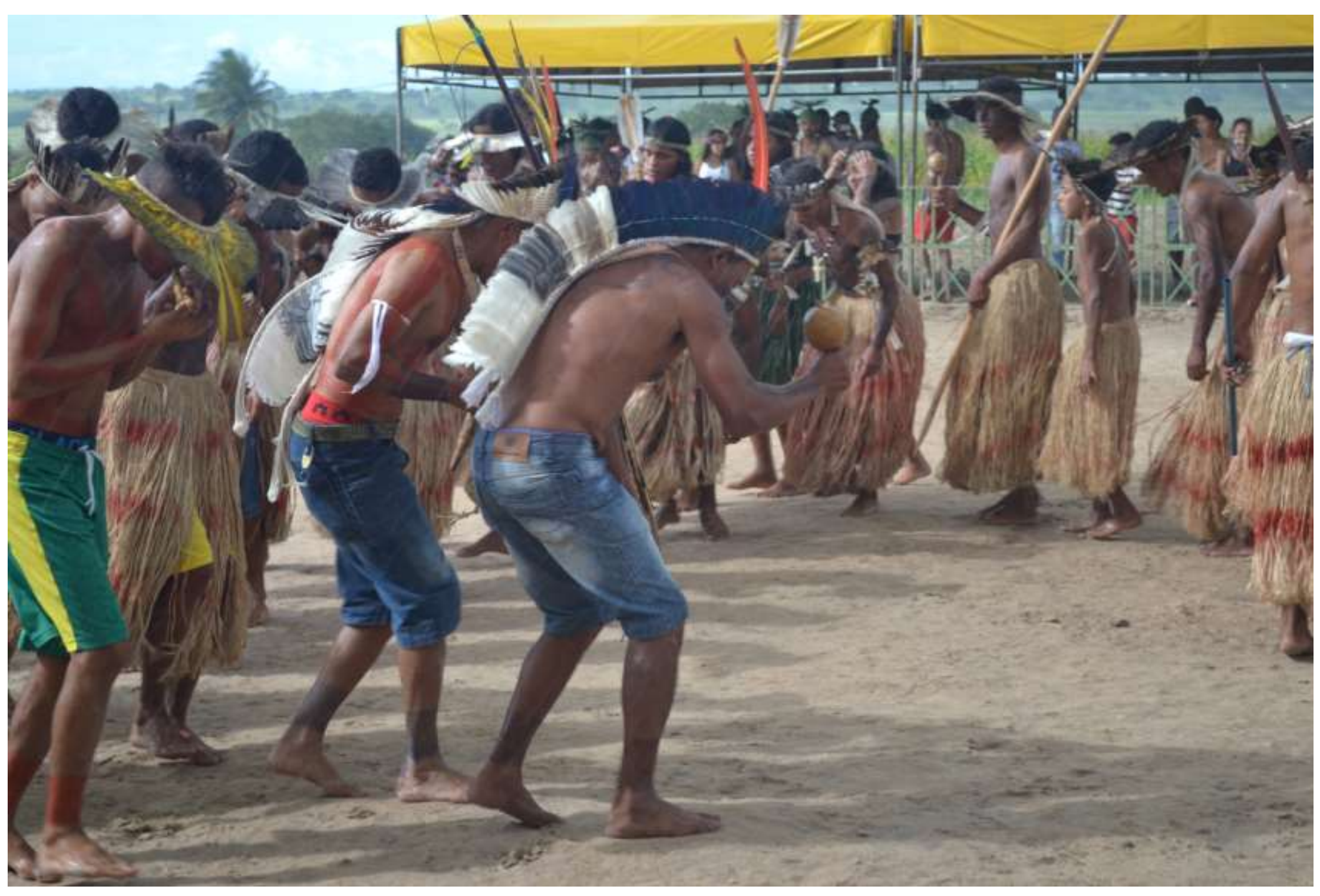

Toré dançado durante Jogos Kalankó

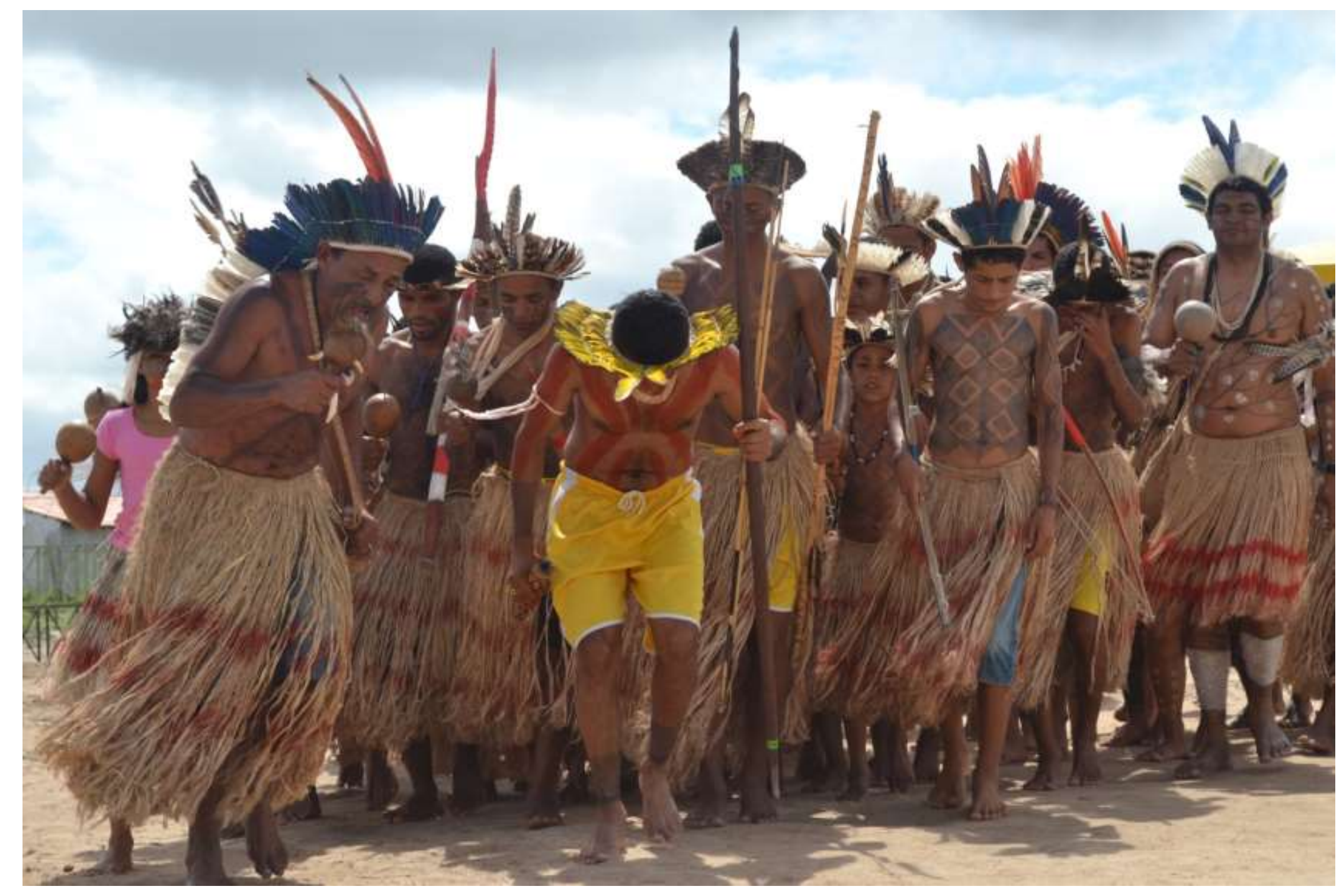

Toré de encerramento dos jogos e festividade dos 19 anos de resistência Kalankó, com a presença dos grupos Xukuru Kariri Wassu Cocal, Katoknn, Koiupanká, Geripanko e Karuazu. 
